\title{
Systematization, distribution and territory of the caudal cerebral artery on the brain's surface of the turkey (Meleagris gallopavo) $^{1}$
}

\author{
Amarílis Díaz de Carvalho²* and Rui Campos ${ }^{3}$
}

\begin{abstract}
Carvalho A.D. \& Campos R. 2014. Systematization, distribution and territory of the caudal cerebral artery on the brain's surface of the turkey (Meleagris gallopavo). Pesquisa Veterinária Brasileira 34(10):1029-1036. Setor de Anatomia Animal, Faculdade de Medicina Veterinária, Universidade Federal do Rio Grande do Sul, Av. Bento Gonçalves 9090, Porto Alegre, RS 91540-000, Brazil. E-mail: amarilis@bnet.com.br

Thirty Meleagris gallopavo heads with their neck segments were used. Animals were contained and euthanized with the association of mebezonium iodide, embutramide and tetracaine hydrochloride ( $\mathrm{T}$ 61, Intervet) by intravenous injection. The arterial system was rinsed with cold saline solution $\left(15^{\circ} \mathrm{C}\right)$, with $5000 \mathrm{IU}$ heparin and filled with red-colored latex. The samples were fixed in $20 \%$ formaldehyde for seven days. The brains were removed with a segment of cervical spinal cord and after, the dura-mater was removed and the arteries dissected. The cerebral carotid arteries, after the intercarotid anastomosis, were projected around the hypophysis, until they reached the tuber cinereum and divided into their terminal branches, the caudal branch and the rostral branch. The rostral branch was projected rostrolateralwards and gave off, in sequence, two collateral branches, the caudal cerebral and the middle cerebral arteries and the terminal branch was as cerebroethmoidal artery. The caudal cerebral artery of one antimere formed the interhemispheric artery, which gave off dorsal hemispheric branches to the convex surface of both antimeres. Its dorsal tectal mesencephalic branch, of only one antimere, originated the dorsal cerebellar artery. In the interior of the cerebral transverse fissure, after the origin of the dorsal tectal mesencephalic artery, the caudal cerebral artery emitted occipital hemispheric branches, pineal branches and medial hemispheric branches, on both antimeres. The caudal cerebral artery's territory comprehended the entire surface of the dorsal hemioptic lobe, the rostral surface of the cerebellum, the diencephalic structures, the caudal pole and the medial surface of the cerebral hemisphere and in the convex surface, the sagittal eminence except for its most rostral third. Due to the asymmetry found in the caudal cerebral arteries' ramifications, the models were classified into three types and their respective subtypes.
\end{abstract}

INDEX TERMS: Turkey, Meleagris gallopavo, cerebral artery, brain vascularization, birds.

RESUMO.- [Sistematização, distribuição e território da artéria cerebral caudal na superfície do encéfalo em peru (Meleagris gallopavo).] Foram utilizadas 30 cabe-

\footnotetext{
${ }^{1}$ Received on April 4, 2014.

Accepted for publication on August 12, 2014.

${ }^{2}$ Programa de Pós-Graduação em Ciências Veterinárias (PPGCV), Faculdade de Veterinária, Universidade Federal do Rio Grande do Sul (UFRGS), Av. Bento Gonçalves 9090, Bairro Agronomia, Porto Alegre, RS 91540-000, Brazil. *Corresponding author: amarilis@bnet.com.br

${ }^{3}$ Laboratório de Anatomia Animal, Departamento de Ciências Morfológicas, Instituto de Ciências Básicas da Saúde (ICBS), UFRGS, Av. Bento Gonçalves 9090, Porto Alegre, RS 91540-000. E-mail: rcampos@ufrgs.br
}

ças com o segmento de pescoço de Meleagris gallopavo. Os animais foram contidos e eutanasiados com a associação de iodeto de mebezônio, embutramida e cloridrato de tetracaína (T 61 Intervet), via endovenosa. 0 sistema arterial foi lavado com solução salina resfriada $\left(15^{\circ} \mathrm{C}\right)$, com $5000 \mathrm{UI}$ heparina e preenchido com látex corado em vermelho. As peças foram fixadas em formaldeído a $20 \%$ por sete dias. 0 encéfalo foi removido com um segmento de medula espinhal, a dura-máter removida e as artérias dissecadas. As artérias carótidas do cérebro, após a anastomose intercarótica, projetaram-se contornando a hipófise até alcançarem o túber cinéreo e dividiram-se em seus ramos terminais, o 
ramo caudal e o ramo rostral. 0 ramo rostral projetou-se rostro-lateralmente emitindo em sequência seus dois principais ramos colaterais, as artérias cerebral caudal e cerebral média terminado-se como artéria cerebroetmoidal. A artéria cerebral caudal de um antímero formava a artéria inter-hemisférica que lançava ramos hemisféricos dosais para a face convexa de ambos os antímeros. Seu ramo tectal mesencefálico dorsal de apenas um antímero originava a artéria cerebelar dorsal. No interior da fissura transversa do cérebro após a origem da artéria tectal mesencefálica dorsal artéria cerebral caudal lançou ramos hemisféricos occipitais, ramos pineais e hemisféricos mediais em ambos os antímeros. 0 território da artéria cerebral caudal compreendeu toda a superfície do hemi lobo óptico dorsal, a face rostral do cerebelo, as estruturas diencefálicas, o polo caudal e a face medial do hemisfério cerebral e na face convexa do hemisfério cerebral a eminência sagital exceto seu terço mais rostral. Devido à assimetria encontrada nas ramificações das artérias cerebrais caudais, foram classificados os modelos em três tipos com seus respectivos subtipos.

INDEX TERMS: Peru, Meleagris gallopavo, artéria cerebral, cérebro, aves.

\section{INTRODUCTION}

The cerebral arteries constitute the main blood transportation via to the brain and play a fundamental role in the maintenance of normal cerebral activities. As the knowledge about the blood supply's need for the brain nervous tissue progresses, there is a motivation for several morphological investigations regarding the cerebral arteries. Concomitantly, the interest in the study of this subject is growing in different animal species.

There are a few studies about the encephalic irrigation in the wild and exotic species. One of the main studies is the classical of De Vriese (1905), which brought important considerations about the phylogenesis and ontogenesis of cerebral arteries models.

Among other authors, we can cite some works related to the brain vascularization of birds, such as Westpfahl (1961) in Gallus gallus (chicken), Kitoh (1962) in Gallus gallus, Vitums (1965) in Zonotrichia leucophrys gambelli (sparrow), Baumel (1967) in birds, Crowe \& Crowe (1979) in Numida meleagris (helmeted guineafowl), Midtgard (1984) in Larus argentatus (herring gull), Campos (1987) in Gallus gallus, Carvalho (2011) in Meleagris gallopavo (turkey) and Nazer (2011) in Struthio camelus (ostrich).

This study aims to describe and systematize the caudal cerebral artery of Meleagris gallopavo, to determine a standard model and territorial area of irrigation, and the main variations in this species. This information contributes for the studies in this area of comparative anatomy, about the phylogentic development of the blood supply to the central nervous system.

\section{MATERIALS AND METHODS}

For this research, 30 brain with the cervical spinal cord segment of 10 male and 20 female young and adult turkeys (Meleagris gallopavo) were used. Discarded animals were provided from Doux Frangosul breeding center, located in Caxias do Sul, State of Rio Grande do Sul, Brazil, 2006.

Animals were contained and euthanized with an association of mebezonium iodide, embutramide and tetracaine hydrochloride $(0.2 \mathrm{ml} /$ animal $)$ with an intravenous injection in the basilica vein of the forelimb. After the removal of the skin, the sternum with the chest muscles was removed. At the opened thoraco-abdominal cavity, the common carotid arteries were cannulated through the brachycephalic trunks. The cranial cava veins were sectioned near the heart. The arterial system of the 30 animals were rinsed with cold saline solution $\left(15^{\circ} \mathrm{C}\right)$, with $5000 \mathrm{IU}$ heparin $(120 \mathrm{ml} / \mathrm{animal})$ and filled with latex colored in red $(20 \mathrm{ml} / \mathrm{ani}-$ mal). Animals remained immersed for one hour in running water for latex polymerization, and next, the neck was sectioned near its insertion in the trunk. Next, a bone window was opened in the skullcap. Pieces were fixed in $20 \%$ formaldehyde for seven days, and after this period, the brain with a segment of the cervical spinal cord was removed from the cranial vault, the dura-mater was removed and the arteries dissected for observation.

Schematic drawings from all brains, with left and right lateral views, dorsal and of the interior of the cerebral fissures of cerebral arteries were prepared with the aid of a magnifying glass ${ }^{4}$. Nomina Anatomica Avium (1993) was used for the designation of studied vessels. To illustrate data documentation, some exemplars were photographed.

\section{RESULTS}

From the left ventricle of the turkey's heart, the aorta artery was originated and projected craniodorsolateralwards to the right to form the aortic arch, in every preparation, since in birds there was the persistence of the aortic arch. This emitted two brachycephalic trunks and from each one of them, the subclavian artery was originated for the thoracic limbs and continued towards the neck as common carotid artery. After a short path, this last gave off the vertebralvagus trunk and continued as internal carotid artery. The right and left internal carotid arteries were close to the ventral median line of the neck, penetrated and coursed the cervical carotid canal, until they reached the base of the cranium, where they abandoned the canal and diverged laterocranialwards and gave off the external carotid artery to the face and continued as cerebral carotid artery.

The cerebral carotid artery penetrated through the carotid canal projecting rostromediallyward and emerging inside the sella turcica, caudaly. At this point, they presented an intercarotic anastomosis of considerable caliber. After this anastomosis, the cerebral carotid arteries projected rostrodorsalwards and countered the hypophysis, until they reached the tuber cinereum (Fig.1 and 2C). The right and left cerebral carotid arteries then divided on their two terminal branches, the caudal branch and the rostral branch.

The caudal branch was projected caudomedialwards in just one antimere and formed the basilar artery, which vascularized the romboenchefalus structures. In the opposite antimere, it originated the ventral tectal mesencephalic artery and the cerebral arterial circle was always opened caudalwards.

\footnotetext{
${ }^{4}$ Magnifying glass with lamp LTS, 5x enlargement; Stemi SV 8, Zeiss, Göttingen, Germany.
} 


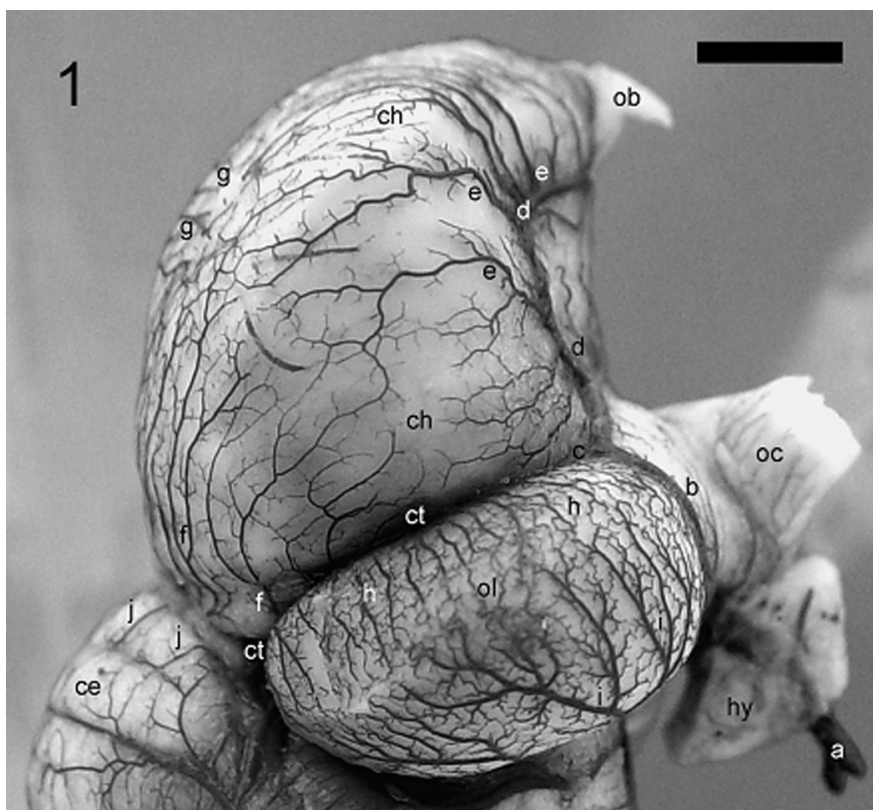

Fig.1. Figure in right lateral view (detail) of the turkey's brain (Obs. 6): (a) cerebral carotid artery (a); (b) rostral branch of a; (c) caudal cerebral artery; (d) middle cerebral artery; (e) lateral hemispheric branches of d; (f) occipital hemispheric branches; (g) dorsal hemispheric branches; (h) branches from the dorsal tectal mesencephalic artery; (i) branches from the ventral tectal mesencephalic artery; (j) branches from the dorsal cerebellar artery; (hy) hypophysis; (oc) optic chiasm; (ol) optic lobe; (ct) cerebral transverse fissure; (ce) cerebellum; (ch) cerebral hemisphere; (ob) olfactory bulb. Bar $=4 \mathrm{~mm}$
The rostral branch was a natural continuation of the cerebral carotid artery, projected rostrolateralwards and gave off, in sequence, its main collateral branches, the caudal cerebral and middle cerebral arteries and the terminal branch as cerebroethmoidal artery (Fig.1 and 2C). Here, the cerebral arterial circle was always opened rostralwards.

The rostral branch of the cerebral carotid artery was a thick caliber vessel, which was projected laterorostralwards, in arch, until it reached the cerebral transverse fissure, between the optic lobe and the cerebral hemisphere. At this point, emitted for the interior of this fissure, its first collateral branch, a medium to thick caliber vessel, the caudal cerebral artery (Fig.1 and 2C).

The caudal cerebral artery, usually single, presented variable calibers between both antimeres, due to the variability in the origin of its ramifications, since normally only the caudal cerebral artery of one antimere formed the interhemispheric artery, which emitted branches for the convex surface of both antimeres. Besides that, normally, its dorsal tectal mesencephalic branch from one antimere only, variable, originated the dorsal cerebellar artery.

The caudal cerebral artery was a single vessel in 100\% of the samples to the right and in $96.7 \%$ to the left, where it was double in $3.3 \%$. It presented caliber variation between both antimeres, where in $50 \%$ of the pieces to the right it had larger caliber than the left caudal cerebral artery. The caudal cerebral arteries, after penetrated the cerebral transverse fissure, gave off a dorsal tectal mesencephalic artery, which in $100 \%$ of the samples in both antimeres, presented as a single vessel. The dorsal tectal mesencepha-
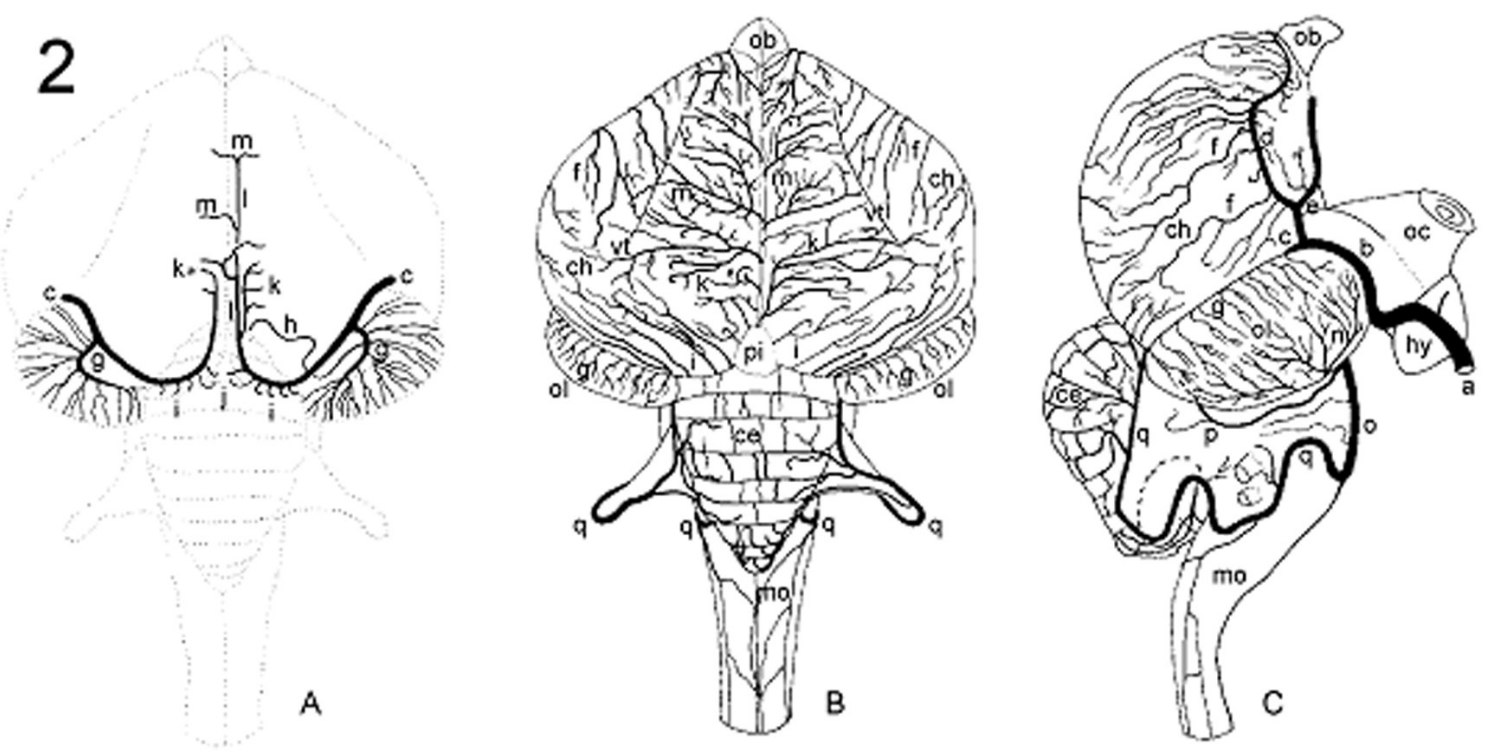

Fig.2. Schematic drawing of the turkey's brain (Obs. 6) in internal views of the fissures (A), dorsal (B) and right lateral (C) to show the distribution of the branches of the caudal cerebral artery: (a) cerebral carotid artery; (b) rostral branch of a; (c) caudal cerebral artery; (d) middle cerebral artery; (e) cerebroethmoidal artery; (f) lateral hemispheric branches of d; (g) dorsal tectal mesencephalic artery; (h) dorsal cerebellar artery; (i) occipital branches from c; (j) pineal branches; (k) medial hemispheric branches; (l) interhemispheric artery; (m) dorsal hemispheric branches; (n) branches from the ventral tectal mesencephalic artery; (o) basilar artery; (p) rostral ventral cerebellar artery; (q) caudal ventral cerebelar artery; (ob) olfactory bulb; (ch) cerebral hemisphere; (vt) telencephalic valecula; (ol) optic lobe; (pi) pineal gland; (ce) cerebellum; (mo) medulla oblongata; (oc) optic chiasm; (hy) hypophysis. 
lic artery formed a caudal arch on the dorsal surface of the optic lobe and gave off a sequence of unilateral arborescent branches, which vascularized the entire dorsal hemiface of the optic lobe (Fig.2A). The dorsal tectal mesencephalic artery of one antimere could originate a dorsal cerebellar artery. In $56.7 \%$ of the pieces, the dorsal tectal mesencephalic artery of only one antimere originated the dorsal cerebellar artery. But in $43.3 \%$ of the samples, the dorsal tectal mesencephalic artery did not originate the dorsal cerebellar artery, in both antimeres. When the dorsal cerebellar artery was absent, its territory, the rostral surface of the cerebellum, was vascularized by vessels provided from other sources, such as branches of the ventral tectal mesencephalic and rostral and caudal ventral cerebellar arteries.

The caudal cerebral artery, inside the cerebral transverse fissure, between the origin of the dorsal tectal mesencephalic artery and the entrance on the interhemispheric fissure, gave off occipital hemispheric branches (Fig. 1-3), which ascended at the caudal surface of the cerebral hemisphere and vascularized the caudal pole. The right caudal cerebral artery gave off for the cerebral hemisphere three occipital hemispheric branches in $46.7 \%$, four branches in $36.7 \%$, five branches in $10 \%$, six branches in $3.3 \%$ and two branches in $3.3 \%$ of the samples. But to the left, the caudal

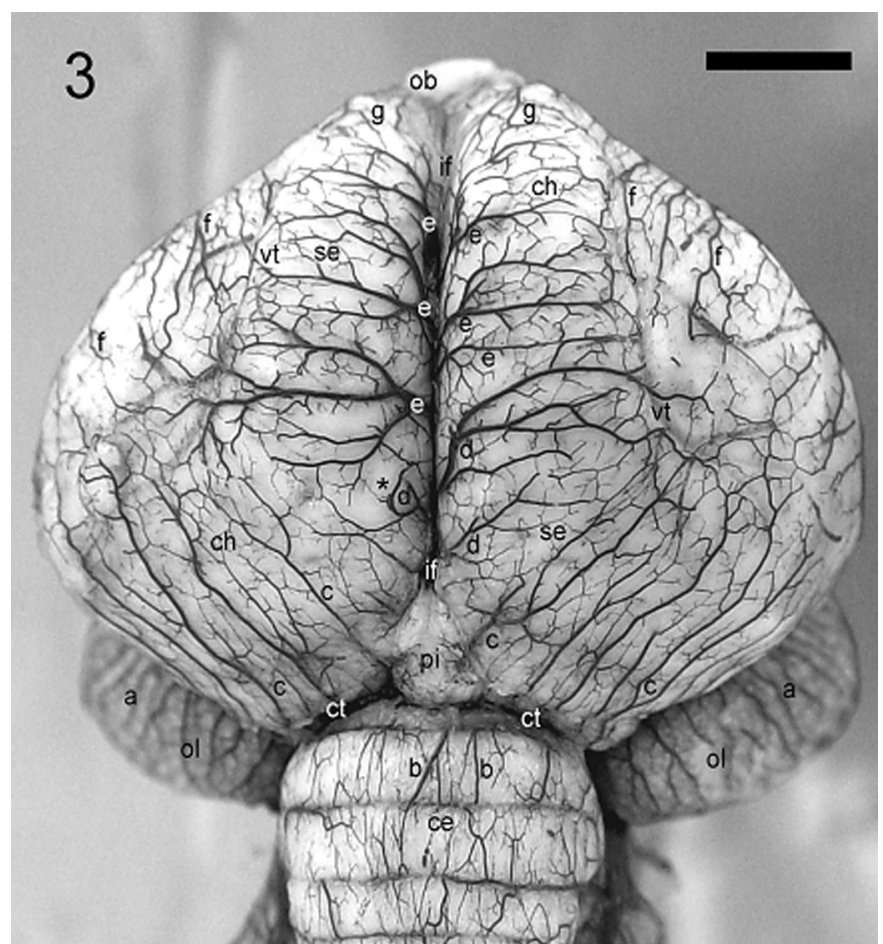

Fig.3. Figure in dorsal view (detail) of the turkey's brain (Obs. 6): (a) branches from the dorsal tectal mesencephalic artery; (b) branches from the dorsal cerebellar artery; (c) occipital hemispheric branches; (d) medial hemispheric branches; (e) dorsal hemispheric branches; (f) lateral hemispheric branches from the middle cerebral artery; $(\mathrm{g})$ rostral hemispheric branches from the middle cerebral artery; (ce) cerebellum; (pi) pineal gland; (if) interhemispheric fissure; (ct) transverse fissure of the brain; (ol) optic lobe; (ch) cerebral hemisphere; (ob) olfactory bulb; (vt) telencephalic valecula; (se) sagittal eminence. Bar $=4 \mathrm{~mm}$ cerebral artery emitted for the cerebral hemisphere three occipital branches in 50\%, four in $26.7 \%$, five in $6.7 \%$, six in $6.7 \%$, two in $6.7 \%$ and one in $3.3 \%$ of the preparations. The caudal cerebral artery from both antimeres, while curving rostralwards to the interior of the interhemispheric fissure gave off pineal branches for the homonymous gland (Fig.2A), located between the cerebral hemispheres and the cerebellum. The pineal arteries were projected medialwards, reached the base of the pineal gland's peduncle and vascularized the adjacent diencephalic structures (habenula, thalamus), ascended through the peduncle until the gland's apex, vascularizing it. In $56.7 \%$ of the samples to the right and $66.7 \%$ to the left, the caudal cerebral artery gave off one pineal branch. But in 20\% to the right and 30\% to the left gave off two pineal branches. But in $13.3 \%$ to the right and $3.3 \%$ to the left, it did not give off a pineal branch, in just one antimere. And only to the right in $10 \%$ it gave off three pineal branches. The caudal cerebral artery, after giving off the pineal arteries, entered the interhemispheric fissure and gave off the medial hemispheric branches, which ascended to the convex surface of the cerebral hemisphere and distributed laterorostralwards in the most caudal part of the sagittal eminence (Fig.2B and 3). The right caudal cerebral artery gave off for the cerebral hemisphere, one medial hemispheric branch in $63.3 \%$, two in $30 \%$ and $6.7 \%$ did not emit a medial hemispheric branch. The dorsal hemispheric artery supplied the corresponded territorial area. But to the left, the caudal cerebral artery gave off for the cerebral hemisphere one medial hemispheric branch in $63.3 \%$, two in $20 \%$, four in $6.7 \%$ and in $10 \%$ did emit a medial hemispheric branch. The dorsal hemispheric artery supplied the corresponded territorial area.

The natural continuation of the caudal cerebral artery, inside the interhemispheric fissure, the interhemispheric artery, was a thick caliber single vessel, usually existent in one antimere only, which formed branches and trunks that distributed in the convex surface of the cerebral hemisphere, on both antimeres (Fig.2A,B and 3). In $53.3 \%$ of the samples to the right and $50 \%$ to the left, the interhemispheric artery was developed and terminal branch of the caudal cerebral artery. In $46.7 \%$ of the pieces to the right and $50 \%$ to the left, the caudal cerebral artery did not form the interhemispheric artery. In sample 11, there was the persistence of the interhemspheric artery, on both antimeres, characterizing the only double case of the interhemispheric artery. The interhemispheric artery gave off a sequence of trunks and branches, which distributed in the convex surface of the cerebral hemisphere on both antimeres, the dorsal hemispheric branches usually went towards one antimere, while the trunks went towards both antimeres. In the interior of the interhemispheric fissure, these branches vascularized the entire medial surface of the cerebral hemisphere an ended rostralwards on a thin branch, close to the olfactory bulb. Its dorsal hemispheric branches were projected laterorostralwards, as they left the interhemispheric fissure, and their terminal extremities reached the telencephalic valeculla and anastomosed in in osculum with the terminations of the lateral hemispheric arteries, from the middle cerebral artery (Fig.2B and 3). The last 
most rostral branches of the interhemispheric artery, the dorsal hemispheric branches, anastomosed with the rostral hemispheric terminal branches from the middle cerebral artery. The interhemispheric artery vascularized the medial surfaces of the cerebral hemisphere and the most central part of the sagittal eminence of the convex surface.

From the verification of an asymmetry in the branches originated by the right and the left caudal cerebral arteries and based on the obtained results, the classification of different types of appearance of these variables was done, taking into account the formation of the interhemispheric artery, the dorsal tectal mesencephalic arteries and the dorsal cerebellar artery (Fig.4). In the asymmetry patterns, Type I was restricted to $20 \%$ of the cases in which the caudal cerebral artery of one antimere gave off the dorsal tectal mesencephalic artery and continued as the single interhemispheric artery, which vascularized the cerebral hemispheres. In the opposite antimere, the caudal cerebral artery gave off the dorsal tectal mesencephalic artery, which originated the dorsal cerebellar artery. The subtypes were subdivided due to the mirror-models found. Subtype IA was composed of four of these pieces, where the predominant interhemispheric artery was observed in the left antimere (Obs. 4, 9, 12 and 24). Subtype IB was found in ony two of these samples, where the predominant interhemispheric artery was found to the right (Obs.3 and 22). Type II corresponded to $36.7 \%$ of the preparations, where the caudal cerebral artery of only one antimere gave off a dor-

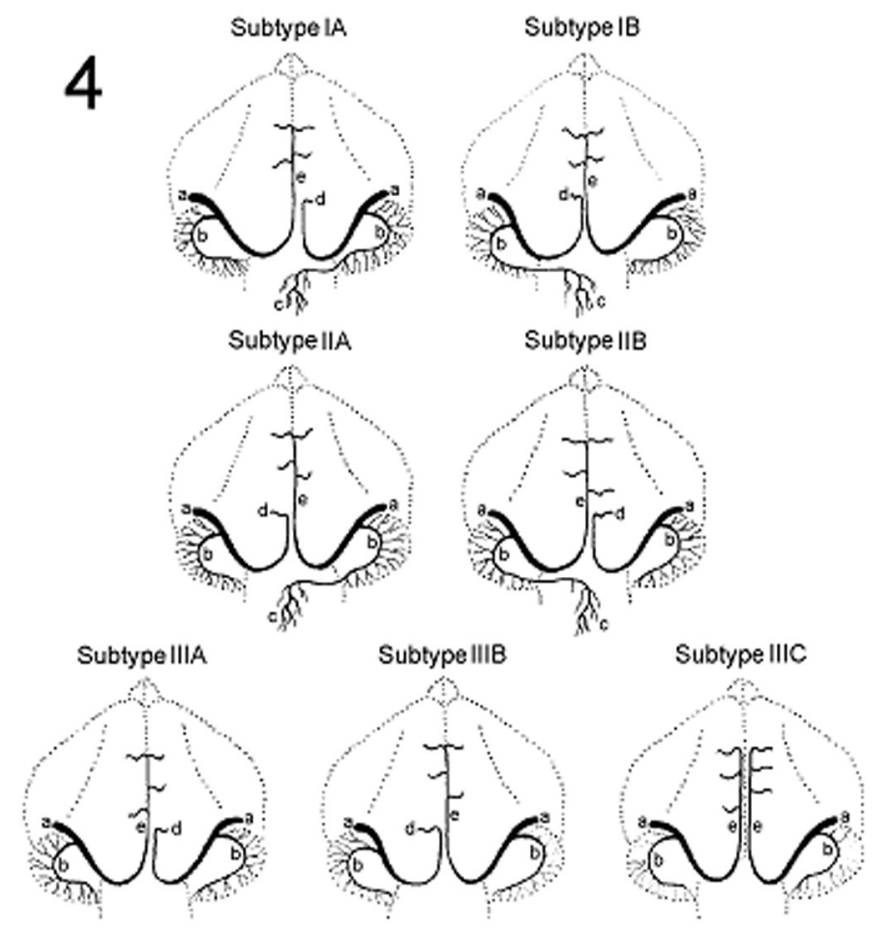

Fig.4. Schematic drawing of the turkey's brain (Obs. 6), in dorsal view, of the classification about the ramification type of the caudal cerebral arteries and their subtypes: (a) caudal cerebral artery; (b) dorsal tectal mesencephalic artery; (c) dorsal cerebellar artery; (d) medial hemispheric branches; (e) interhemispheric artery. sal tectal mesencephalic artery, which originated the dorsal cerebellar artery and continued as single interhemispheric artery. In the opposite antimere, the caudal cerebral artery gave off the dorsal tectal mesencephalic artery and did not form the interhemispheric artery. Subtype IIA was composed by nine of these cases, with the predominant interhemispheric artery and the dorsal cerebellar artery to the right (Obs.1, 2, 5, 8, 16, 20 and 21). Subtype IIB occurred in two of these cases, where the predominant interhemispheric artery was to the left, as well as the dorsal cerebellar artery (Obs. 18 and 30). Type III prevailed in $43.3 \%$ of the samples. The caudal cerebral artery and its branches did not originate the dorsal cerebellar artery and the territory was supplied by vessels provided from another source, that is, by the ventral tectal mesencephalic artery, the rostral ventral cerebellar or the caudal ventral cerebellar arteries. Subtype IIIA was represented by eight of these samples, where the caudal cerebral artery from the left antimere originated the left dorsal tectal mesencephalic artery, and continued as the predominant interhemispheric artery. In the opposite antimere, the right caudal cerebral artery formed only the right dorsal tectal mesencephalic artery. Here (Obs. 13, 15, 19, 25, 26, 28 and 29), the dorsal cerebellar artery's territory was supplied by branches of the ventral tectal mesencephalic artery, provided from both antimeres. In one sample (Obs. 10), the territory of the dorsal cerebellar artery was supplied by branches provided from the left ventral tectal mesencephalic artery. Subtype IIIB was composed by four of these samples, in which a mirror occurred, and the right caudal cerebral artery gave off the dorsal tectal mesencephalic artery, continued as predominant interhemispheric artery. In the opposite antimere, the left caudal cerebral artery gave off the left dorsal tectal mesencephalic artery and did not form the interhemispheric artery. In these samples (Obs. 14, 17 and 27), the territory of the dorsal cerebellar artery was supplied by branches from the ventral tectal mesencephalic artery provided from both antimeres. In one sample (Obs. 23), the caudal ventral cerebellar arteries, from both antimeres, supplied the cited territory. Subtype IIIC was represented by one sample in which the caudal cerebral artery from both antimeres gave off a dorsal tectal mesencephalic artery, continued as interhemispheric artery, characterizing only one case of double persistence of this vessel in the turkey. In this sample (Obs. 11), the territory of the dorsal cerebellar artery was supplied by the left rostral ventral cerebellar artery, plus the branches from the left ventral tectal mesencephalic artery. While in the right antimere, this territorial area was supplied by branches from the right caudal ventral cerebellar artery.

The caudal cerebral artery's territory comprehended the surface of the dorsal hemioptic lobe, the rostral surface of the cerebellum, the diencephalic structures (thalamus, habenullae and pineal gland), the caudal pole and the medial surface of the cerebral hemisphere and in the convex surface of the cerebral hemisphere the sagittal eminence, except for its most rostral third. The occipital hemispheric branches anastomosed with the first lateral hemispheric branches from the middle cerebral artery. The dorsal he- 
mispheric branches anastomosed in osculum with the terminations of the lateral hemispheric branches, at the level of the telencephalic vallecula and rostralwards with the rostral terminal branches of the middle cerebral artery, at the rostral third of the sagittal eminence (Fig.3).

\section{DISCUSSION}

According to De Vriese (1905), the cerebral carotid artery divided beside the hypophysis in a thick rostral branch and a medium caudal branch (Westpfahl, 1961, Richards 1967. Crowe 1979, Midtgard 1984, Campos 1987, Campos et al. 1995), with the same found in the turkey. But Kitoh (1962), which studied Gallus gallus, observed that the rostral and caudal branches had almost the same caliber.

In the turkey, the caudal branch of the cerebral carotid artery, when developed, originated as collateral branch the ventral tectal mesencephalic artery (Richards 1967) and continued as basilar artery. But in the opposite antimere, the caudal branch projeted from the cerebral carotid artery as ventral tectal mesencephalic artery (Campos 1987, Campos et al. 1995, Carvalho 2011).

In the turkey, the rostral branch was the natural continuation of the cerebral carotid artery (Vitums 1965), a thick caliber vessel, which was projected in arch, until it reached the cerebral transverse fissure (Campos 1987, Campos et al. 1995, Carvalho 2011). It was also observed in the turkey and in Gallus gallus (Campos 1987, Campos et al. 1995) that this rostral branch presented as collateral branches the caudal cerebral artery and the middle cerebral artery. Its terminal branch was the cerebroethmoidal artery (Crowe \& Crowe 1979, Baumel 1981, King \& McLelland 1981, Carvalho 2011). But for Westpfahl (1961) in the studies about Gallus gallus, the rostral branch ran laterorostralwards the ventral surface of the middle brain and reached the cerebral transverse fissure, where it gave off the caudal cerebral artery, ran between the mesencephalus and the cerebral hemisphere and reached the dorsal surface of the brain, to divide there in its terminal branches. After the origin of the caudal cerebral artery, the rostral branch ramified forming the middle cerebral artery and the ethmoidal artery. For Richards (1967) in Gallus gallus, the rostral branch was larger and responsible for the blood supply to the cerebral hemisphere, running rostrolateralwards around the optic chiasm to originate the main three cerebral arteries: caudal, middle and rostral cerebral. But in the turkey, the rostral branch of the cerebral carotid artery, after the emission of the caudal cerebral artery, gave off the middle cerebral artery, but continued as cerebroethmoidal artery and this, after had given off the rostral cerebral artery, continued as ethmoidal artery. For Crowe (1979) in his study about the head and neck blood distribution, in guinea fowl, observed that the rostral branch originated the ventral tectal mesencephalic artery. The rostral branch passed rostrolateralwards around the brain to originate four branches: caudal cerebral, middle cerebral, cerebroethmoidal and rostral cerebral arteries (Vitums 1965, Baumel 1981, Midtgard 1984).

Regarding the presence of the caudal cerebral artery, for Nazer (2011) in ostrich, this was presented double, either to the right or to the left, in the majority of the samples, on contrast to the turkey, in which only one sample to the left antimere was double (Carvalho 2011). For Campos (1987) in Gallus gallus, the right and the left caudal cerebral arteries were presented, in all brains, as single vessels.

For Crowe (1979) in guinea fowl, the caudal cerebral artery was more developed in the right antimere, in three specimens out of eight. In the turkey, there was no antimere prevalence, because in half of the samples, the caudal cerebral artery was larger in one or in the other antimere.

For Richard (1967) in Gallus gallus, the caudal cerebral artery went lateralwards at the beginning, but soon turned dorsalwards between the optic lobe and the cerebral hemisphere, forming the dorsal tectal mesencephalic artery (Kitoh 1962, Vitums 1965, Carvalho 2011, Nazer 2011). This was also observed in the turkey.

According to Baumel (1981), the dorsal cerebellar artery was a single extension of the dorsal tectal mesencephalic artery, that is, only received this denomination when originated from this source (dorsal tectal mesencephalic artery). In the turkey, in the majority of the samples, there was the emission of the dorsal cerebellar artery, originated from the dorsal tectal mesencephalic artery, from either each one antimere (Campos 1990). But for Kitoh (1962) in Gallus gallus, the left caudal cerebral artery originated the interhemispheric and the dorsal cerebellar artery (Richard 1967).

According to Kitoh (1962) in Gallus gallus, the caudal cerebral artery of one antimere was distributed only over the caudal pole of the cerebral hemisphere. In the opposite antimere, it gave off branches for the caudal pole of the cerebral hemisphere and one branch for the cerebellum, which went caudalwards and distributed on the cerebellum as dorsal cerebellar artery (Vitums 1965, Richard 1967, Midtgard 1984). In Meleagris gallopavo the caudal cerebral artery gave off a dorsal tectal mesencephalic artery and in the majority of the cases, in only one antimere, the dorsal cerebellar artery was the terminal branch, which vascularized the rostral surface of the cerebellum (Carvalho 2011, Nazer 2011).

According to Kitoh (1962) in Gallus gallus, the caudal cerebral artery originated from one to three collateral branches, which distributed at the caudal pole of the telencephalon (Midtgard 1984, Baumel 1981, Campos 1990). This distribution observed by the authors above was similar to what was found in the turkey, however in the caudal cerebral artery's trajectory, between the origin of the dorsal tectal mesencephalic artery and the entrance of the interhemispheric fissure, it gave off from one to six occipital hemispheric branches, which ascended to the caudal surface of the cerebral hemisphere and vascularized the caudal pole, until the caudal limit of the telencephalic vallecula, and anastomosed with the lateral hemispheric branches of the middle cerebral artery.

In Meleagris gallopavo, the caudal cerebral artery, after the emission of the occipital hemispheric branches inside the interhemispheric fissure, gave rise to, in most of the cases, in both antimeres, a collateral branch to the pineal gland (Campos 1990, Kitoh 1962). For Vitums (1965) in 
sparrows, usually only one pineal branch is given off by the dorsal cerebellar artery, in one antimere.

In the turkey, the caudal cerebral artery, after the origin of the pineal artery, gave off one single medial hemispheric branch, in both antimeres, which ascended to the convex surface of the cerebral hemisphere. This branch distributed laterorostralwards the most caudal third of the sagittal eminence. In one antimere, the medial hemispheric branch was the terminal branch of caudal cerebral artery, while in the opposite antimere, formed a single interhemispheric artery in most of the samples. No author, in the literature, reported the presence of these medial hemispheric branches, and this area was supplied by the dorsal hemispheric branches of the interhemispheric artery and by the occipital hemispheric branches of the caudal cerebral artery (Campos 1990).

For Campos (1990) in Gallus gallus, the caudal cerebral artery of one antimere was predominant and formed the interhemispheric artery (Kitoh 1962, Richard 1967, Baumel 1981, Carvalho 2011) in agreement with the description found in the turkey. For Vitums (1965) in sparrows, in two cases, the right and left caudal cerebral arteries united at the end of the interhemispheric fissure and formed an interhemispheric artery, which extended along this fissure almost until the rostral end of the cerebral hemispheres, where it gave off several small branches for both hemispheres.

According to Nazer (2011), in ostrich, the interhemispheric artery gave off dorsal hemispheric branches for both cerebral hemispheres, similar to what was found in Meleagris gallopavo (Vitums 1965, Baumel 1981, Campos 1990, Carvalho 2011). Still for the same author, the dorsal hemispheric branches of the interhemispheric artery anastomosed with the lateral hemispheric branches of the middle cerebral artery (Vitums 1965, Campos 1990). This anastomosis was also observed in the turkey.

In the turkey, an asymmetry was observed regarding the branches originated by the left and right caudal cerebral arteries. Therefore, the appearance behavior of these variants was classified in different types, based on Baumel (1967) classification. In Type I the caudal cerebral artery, of one antimere, gave off the dorsal tectal mesencephalic artery and continued as interhemispheric artery. On the opposite antimere, the caudal cerebral artery gave off the dorsal tectal mesencephalic artery, which originated the dorsal cerebellar artery (Campos 1990). Baumel (1967) in different avian species also classified the ramification of the caudal cerebral artery in different types, in which in Type I, the caudal cerebral artery gave off the interhemispheric artery, depending on the antimere. And on the opposite antimere, it gave off only the dorsal cerebellar artery, therefore this author do not cite the formation of a dorsal tectal mesencephalic artery. For Vitums (1965), in sparrows, the same formation occurred, however he describes that presence of the dorsal tectal mesencephalic artery as an isolated branch of the caudal cerebral artery in both antimeres. Still in the turkey in Subtype IA the left caudal cerebral artery, after the emission of the dorsal tectal mesencephalic artery, continued as predominant interhemipheric artery.
On the opposite antimere, the right caudal cerebral artery originated a dorsal tectal mesencephalic artery, which continued as single dorsal cerebellar artery (Campos 1990). It was also described in Meleagris gallopavo, the Subtype IB, in which a mirror occurred of Subtype IA, in a small number of samples (Campos 1990).

Another found classification in the turkey was Type II, in which the right caudal cerebral artery gave off the interhemispheric, the dorsal tectal mesencephalic and the dorsal cerebellar arteries. Whereas, in the opposite antimere, only the dorsal tectal mesencephalic artery was given off by the left caudal cerebral artery. This type was also subdivided in Subtype IIA, where there was a dominance, on the right antimere, of the presence of the interhemispheric, dorsal tectal mesencephalic and dorsal cerebellar arteries and in Subtype IIB, in which a mirror of the arteries occurred in a few samples (Campos 1990). It was observed by Campos (1990) in Subtype IIB, in just one piece, an anatomical variation with the presence of a right accessory interhemispheric artery, which crossed to the convex surface of the opposite antimere, configuring duplicity of the interhemispheric artery. In the turkey, it was also observed, in one sample, duplicity of the interhemispheric artery, however with absence of the dorsal cerebellar artery in both antimeres. In these cases the cerebellum was supplied by a source that was not part of the caudal cerebral system (Type III - Subtype IIIC). Baumel (1967), classified in Type II the caudal cerebral artery originating the interhemispheric and the dorsal cerebellar arteries (singles) of a same antimere (variable) and did not cite the presence of a dorsal tectal mesencephalic artery. In this same classification, Vitums (1965) described the presence of an isolated dorsal tectal mesencephalic artery as branch of the caudal cerebral artery, in either one antimere.

The last classification observed in the turkey, denominated Type III, was a non-emission of the dorsal cerebellar artery by the caudal cerebral system. In these cases, the cerebellum was supplied by a vessel provided from other sources, such as the ventral tectal mesencephalic artery (caudal branch of the cerebral carotid artery or the collateral branch of the caudal branch of the cerebral carotid artery) and the rostral and caudal ventral cerebellar arteries (branches of the basilar artery). Baumel (1967) also observed modified types in which the blood supply to the cerebellum was originated from other sources, whether than the caudal cerebral system. In the turkey the caudal ventral cerebellar artery was the main source of the blood supply to the cerebellum like one of the findings by Baumel. Still for this author, other sources like the rostral choroid artery and branches of the rostral cerebral artery also supplied the cerebellum, fact that was not found in the turkey. In the turkey Type III was subdivide in Sutype IIIA, IIIB and IIIC. In Subtype IIIA the left caudal cerebral artery originated the interhemishperic and the left dorsal tectal mesencephalic arteries and the right caudal cerebral artery gave off only the right dorsal tectal mesencephalic artery. In Subtype IIIB a Subtype IIIA-mirror occurred, which corresponded to the classification of Campos (1990) Subtype IIIA in Gallus gallus. 
Another subdivision observed by Campos (1990) was the Subtype IIIB, in which the left caudal cerebral artery only gave off the left dorsal tectal mesencephalic artery and the caudal cerebral artery of the opposite antimere gave off only the interhemispheric artery, which was not observed in any of the samples in Meleagris gallopavo. In Subtype IIIC of the turkey, there was duplicity of the interhemispheric arteries, with each one originated from a correspondent caudal cerebral artery. These caudal cerebral arteries also originated, for each antimere, the right and left dorsal tectal mesencephalic arteries. With that, the cerebellum was supplied, in the right antimere, by the caudal ventral cerebellar artery (branch of the basilar artery) and on the opposite antimere, by the rostral ventral cerebellar artery (branch of the basilar artery) and by the ventral tectal mesencephalic artery (collateral branch of the caudal branch of the cerebral carotid artery). Baumel (1967) also observed, in birds, duplicity of the interhemispheric artery being classified in Subtype IIIB and Type IV. Baumel (1967) cites a type IV, where the main branch of the caudal cerebral arteries is essentially symmetric. Both interhemispheric branches and the dorsal cerebellar arteries are paired and have equivalent distribution on each one of the cerebral antimeres. This type was found in falconiformes (Accipiter and Buteo).

According to Campos (1990) in chickens, the territorial area of the caudal cerebral arteries comprehended an area that included the dorsal surface of the cerebral hemispheres, caudalwards the telencephalic valleculas, the medial surface of the cerebral hemispheres with the exception of a small rostral part, the caudal poles and the caudal surface from both cerebral hemispheres. Also for the same author, the caudal cerebral artery irrigated the pineal gland, the dorsal surfaces of the two tectal mesencephalic optic lobes and the rostral ventral cerebellar lobules, until the first dorsal cerebellar lobulus, with the same result found in Meleagris gallopavo (Kitoh 1962).

\section{CONCLUSIONS}

The caudal cerebral arteries of the turkey are characterized for presenting, in their ramifications, an asymmetry standard in which the interhemispheric artery of only one antimere is developed.

Its branches vascularize a territory comprehended by the surface of the dorsal hemioptic lobe, the caudal pole of the medial surface of the cerebral hemispheres and on the convex surface, most part of the sagittal eminences, besides the pineal gland and diencephalic structure.

Acknowledgements.- To CAPES (Coordenação de Aperfeiçoamento de Pessoal de Nível Superior) for the financial support of this study.

\section{REFERENCES}

Baumel J.J. 1967. The characteristic asymmetrical distribution of the posterior cerebral artery of birds. Acta Anat. 67:523-549.

Baumel J.J. 1981 Coração e vasos sangüíneos das aves, p.1842-1869. In: Getty R. (Ed.), Sisson/Grossman's Anatomia dos Animais Domésticos. Vol.2. 5 a ed. Interamericana, Rio de Janeiro

Baumel J.J., King A.S., Breazile J.E., Lucas A.M. \& Evans H.E. 1993. Handbook of Avian Anatomy: Nomina anatomica avium. Nuttal Ornithological Club, Cambridge.

Campos R. 1987. Contribuição ao estudo do comportamento das artérias carótidas na base do encéfalo em Gallus gallus. Dissertação de Mestrado em Anatomia Animal, Faculdade de Medicina Veterinária e Zootecnia, USP, São Paulo, SP. 141p.

Campos R. 1990. Contribuição ao estudo do comportamento e distribuição das artérias cerebral média, cerebral caudal e cerebelar ventral caudal na superfície do encéfalo em Gallus gallus. Tese de Doutorado em Anatomia Animal, Faculdade de Medicina Veterinária e Zootecnia, USP, São Paulo, SP. 155p.

Campos R., Ferreira N. \& Marrone A.C.H. 1995. A systematic study of encephalic blood supply in Gallus gallus. J. Anat. Embryol. 100:111-121.

Carvalho A.D. \& Campos R. 2011. A systematic study of the brain base arteries in the turkey (Meleagris gallopavo). Pesq. Vet. Bras. 31(Supl.1):3946.

Crowe T.M. \& Crowe A.A. 1979. Anatomy of the vascular system of the head and neck of the helmeted guinea fowl Numida meleagris. J. Zool. 188:221-233.

De Vriese B. 1905. Sur la signification morphologique des artères cérébrales. Archs Biology 21:357-457.

Kitoh J. 1962. [Comparative and topographical anatomy of the fowl. XII. Observation on the arteries with their anastomoses in and around the brain in the fowl] (in japanese). Jpn. J. Vet. Sci. 24:141-150.

Midtgard U. 1984. The blood vascular system in the head of the herring gull (Larus argentatus). J. Morphol. 179:135-152.

Nazer M.B. \& Campos R. 2011. Systematization of the brain base arteries in ostrich (Struthio camelus). J. Morphol. Sci 28:268-274.

Richards S.A. 1967. Anatomy of the arteries of the head in the domestic fowl. J. Zool. 152:221-234.

Westpfahl U. 1961. Das Arteriensystem des Haushuhnes (Gallus domesticus). Wissenschaftliche Zeitschrift der Humboldt 10:93-124.

Vitums A., Mikami S.I. \& Farner D.S. 1964. Arterial blood supply to the brain of the white-crowned sparrow (Zonotrichia leucophrys gambelii). Anat. Anz. 116:309-326. 